\title{
Sustentabilidade e Contabilidade
}

\author{
Sustainability and Accounting
}

\section{Cassio Luiz Vellani}

Mestre em Contabilidade na Faculdade de Economia, Administração e Contabilidade de Ribeirão Preto da Universidade de São Paulo.

Professor do curso de Ciências Contábeis da Faculdade COC

Professor do curso de Administração da Universidade de Ribeirão Preto

Endereço: Rua João Perone, 245, apto 11 - Nova Aliança.

CEP: 14026-587 - Ribeirão Preto/SP - Brasil

E-mail: empresaecologica@yahoo.com.br

Telefone: (16) 3234-5854 ou (16) - 8179-9190

\section{Maisa de Souza Ribeiro}

Doutora em Controladoria e Contabilidade na Universidade de São Paulo

Professora do Mestrado em Controladoria e Contabilidade do

Departamento de Contabilidade da FEA-RP/USP

Endereço: Avenida dos Bandeirantes, 3900 - Bairro Monte Alegre

CEP: 14040-900 - Ribeirão Preto/SP - Brasil

E-mail: maisorib@usp.br

Telefone: (16) 3602-4747

Artigo recebido em fevereiro de 2008. Passou por uma avaliação double blind review em novembro de 2008. Aceito em junho de 2009 pela Editora Científica Sandra Rolim Ensslin. Artigo apresentado no IX Simpósio de Administração da Produção, Logística e Operações Internacionais (SIMPOI), 2006, São Paulo, 2006. 


\title{
Resumo
}

Há no mercado divulgação de gastos incorridos em atividades não relacionadas com a sustentabilidade ecológica, como gastos ambientais. Para evitar isso, é necessário compreender o fato gerador do gasto ambiental. O objetivo deste trabalho é investigar, analisar e identificar o tipo de evento relacionado com o fato gerador do gasto ambiental para melhorar a informação sobre as atividades que visam à sustentabilidade ecológica dos negócios. Este trabalho analisa certos conceitos, limita o campo de atuação da Contabilidade da gestão ambiental, propõe um conceito chamado de O Sistema Empresa Ecoeficiente e o analisa e o compara com determinados casos práticos.

Palavras-chave: Sustentabilidade Empresarial, Contabilidade da Gestão Ambiental, Gastos Ambientais.

\begin{abstract}
There is market disclosure of expenses incurred in activities not related to ecological sustainability, as environmental costs. To avoid this, you must understand the environmental costs fact. The objective of this study is to investigate, analyze and identify the type of event related to the environmental costs fact. This study examines certain concepts, limits the action field of environmental management accounting, proposes a concept called The System Company Eco-efficient and analyzes and compares with some practical cases.
\end{abstract}

Key words: Corporate Sustainability, Environmental Management Accounting, Environmental Costs.

\section{Introdução}

As empresas são sistemas que interagem com outros sistemas formando um todo. Quando um sistema não se desenvolve, o todo não pode se manter. Com base nesse raciocínio, as firmas podem ponderar a sustentabilidade em seus processos decisórios e inseri-la no planejamento estratégico visando à continuidade de seus negócios (da parte) e da sociedade em geral (do todo).

Sustentabilidade qualifica tudo aquilo que pode se manter. Sustentar pode ter muitos significados. Um deles pode ser atributo a algo ininterrupto, cíclico, com perspectiva de continuidade.

Nesse sentido, Kates et al. (2003) considera a situação atual do mundo como insustentável. Com uma sociedade em crescimento, globalizada, interconectada e desigual, a humanidade não está conseguindo manter a sustentabilidade dos ecossistemas que suportam a vida na Terra.

As sociedades nascem e se desenvolvem por meio de organizações, instituições e empresas que operam para atender às necessidades das pessoas. Erigir um desenvolvimento sustentável pode significar organizações, instituições e empresas atuando em suas regiões para satisfazerem as necessidades da população presente sem comprometer a capacidade das futuras gerações em satisfazerem suas próprias necessidades.

Para isso, são necessárias várias pequenas mudanças na cultura, nos paradigmas e nos negócios da humanidade. Uma dessas mudanças é a inserção da sustentabilidade nos processo de decisão das organizações, das instituições e 
principalmente das empresas.

No contexto dos negócios, a sustentabilidade pode ter três dimensões: a econômica, a social e a ecológica. Essas dimensões são conhecidas internacionalmente como Triple Bottom Line (TBL) da sustentabilidade de um negócio.

O Conceito TBL reflete sobre a necessidade de as empresas ponderarem em suas decisões estratégicas o bottom line econômico, o bottom line social e o bottom line ambiental, mantendo: a sustentabilidade econômica ao gerenciar empresas lucrativas e geradoras de valor; a sustentabilidade social ao estimular a educação, cultura, lazer e justiça social à comunidade; e a sustentabilidade ecológica ao manter ecossistemas vivos, com diversidade.

Conforme a Figura 1, há interações entre os três bottom line da sustentabilidade:

Figura 1: Interações do Triple Bottom Line (TBL) da sustentabilidade

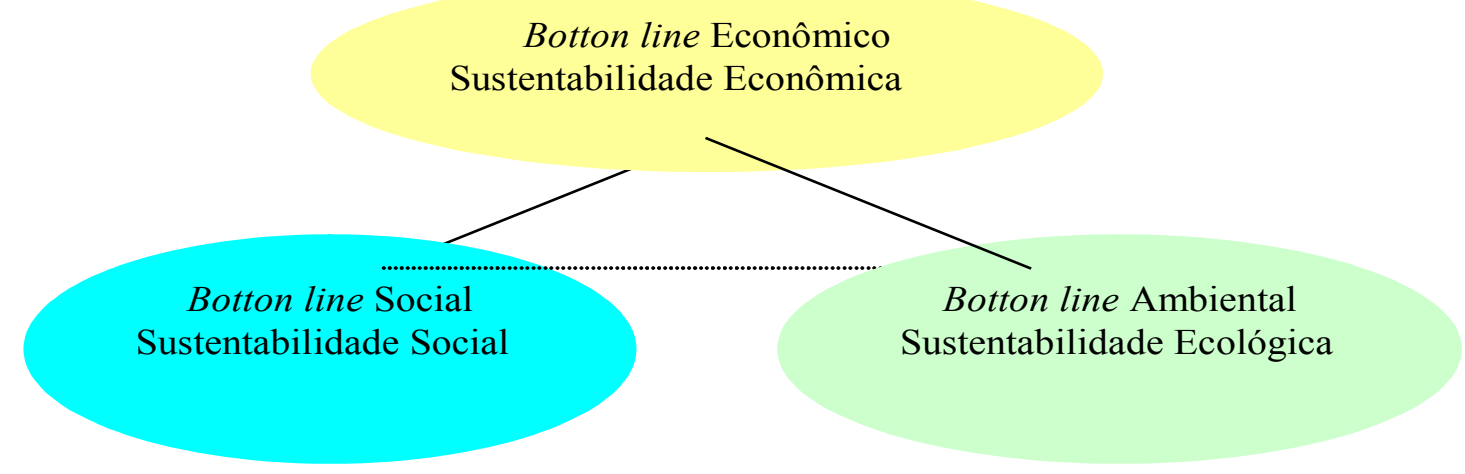

Fonte: Baseado em CES-FGV (2006) e em Sustainablemeasures (2006).

Observa-se que as características e a sustentabilidade das comunidades são o resultado das interações entre o meio ambiente, a economia e a sociedade. Assim, muitas empresas interessadas no desenvolvimento sustentável podem investir no bottom line econômico, no bottom line social e no bottom line ambiental.

Como fonte de informações úteis para tomadas de decisões em relação aos eventos incorridos nas atividades dos bottom lines da sustentabilidade, as empresas podem utilizar a Contabilidade.

De acordo com Bebbington (2001), a Contabilidade como fonte de informação sobre a contribuição da empresa ao desenvolvimento sustentável pode coletar, analisar, mensurar e divulgar informações sobre a relação da empresa com o social, com o econômico e com o ecológico.

Ribeiro e Carvalho (2000a) também defendem a necessidade de a Contabilidade informar de forma eficaz sobre a contribuição das empresas ao desenvolvimento sustentável.

Nesse sentido, as empresas podem organizar seus sistemas de informações 
para possibilitar o gerenciamento de todos os gastos e resultados envolvidos em atividades dos três bottom lines da sustentabilidade.

Mesmo sendo de extrema importância o estudo das fontes de informações dos três bottom lines para a evolução da sustentabilidade, este trabalho estuda apenas a fonte de informação da sustentabilidade ecológica.

Ser sustentável no bottom line ambiental pode significar novos dispêndios de capital e de novos resultados. Ou seja, nos eventos relacionados com a proteção do meio ambiente, gastos são incorridos pelas empresas em atividades cuja finalidade é manter a sustentabilidade ecológica dos sistemas vivos por meio de uma relação equilibrada entre o sistema empresa e os ecossistemas ao seu redor.

Visando ao gerenciamento dos gastos envolvidos nessas atividades ecológicas, as empresas podem utilizar a Contabilidade Ambiental para obter informações úteis para tomada de decisões e para reportar aos interessados informações sobre os eventos relacionados com a sustentabilidade no botton line ambiental.

No entanto, para controlar os recursos consumidos nas atividades ecológicas, os ganhos resultantes e, principalmente, para reportar informações sobre a relação da empresa com o meio ambiente, é necessário ter o conhecimento do fato gerador dos gastos ambientais e conhecer as características das atividades em que incorrem esses gastos.

Em alguns casos, a empresa não tem conhecimento do evento relacionado como fato gerador dos gastos ambientais. Por causa disso, o fornecimento da informação contábil-ecológica pode ser feita de forma equivocada provocando falta de transparência, por exemplo, utilizar certo indicador como medidor do botton line ambiental quando, na verdade, não indica se o negócio está sendo sustentável ecologicamente.

Por causa disso, indicadores de sustentabilidade relacionados com o bottom line econômico, ou com o social, podem ser utilizados equivocadamente como indicador do bottom line ecológico gerando informações distorcidas sobre a sustentabilidade ecológica dos negócios, e, consequentemente, decisões podem ser tomadas com base em números errados.

Aponta-se, como exemplo, que certos gastos incorridos em atividades de jardinagem são considerados como gastos em atividades ambientais, quando, na verdade, são gastos operacionais gerais ou administrativos semelhantes a gastos com manutenção ou despesas com limpeza. Colocar esse gasto como custo ambiental de certo produto, certamente, gera informação errada sobre o custo ecológica desse produto.

Outro tipo de equívoco pode ser a divulgação de um projeto de preservação de determinada área (totalmente desvinculada das atividades dos negócios da empresa) como gasto ambiental, quando, na verdade, pode ser uma ação de sustentabilidade social ao preservar a fauna e a flora de alguma área, mas não 
sustentabilidade ecológica, pois não reduz o consumo de insumo, nem protege o meio ambiente dos resíduos emitidos pela empresa.

Em outro caso, gastos com educação ambiental podem ser divulgados erroneamente como gastos em meio ambiente, quando, por causa de suas características de projeto educacional, estão mais próximos de gastos em atividades relacionadas com o botton line social.

Será que essas empresas estão sendo sustentáveis ecologicamente com essas atividades? Será que programas de educação ambiental à comunidade e preservação de áreas desvinculadas dos processos produtivos das empresas podem ser considerados como ações de sustentabilidade ecológica?

Essas distorções nas informações podem atrapalhar a identificação e o gerenciamento dos gastos e resultados incorridos nas atividades em prol da sustentabilidade ecológica. E como esses gastos incorridos nas atividades ecológicas também podem gerar passivos ambientais - quando o pagamento do gasto ambiental não é feito no período da ocorrência de seu fato gerador - pode gerar informação errada sobre o passivo ambiental da empresa.

O segmento da Contabilidade que pode reduzir os equívocos no fornecimento de informações relacionados com a sustentabilidade ecológica pode ser a Contabilidade Ambiental. Ao limitar o seu campo de atuação, pode possibilitar uma comunicação correta e transparente sobre os eventos realmente relacionados com a sustentabilidade de certo negócio no botton line ambiental, isto é, informação sobre os eventos relacionados ao fato gerador dos gastos ambientais.

A Contabilidade Ambiental pode ser capaz de fornecer informações sobre os gastos e resultados incorridos nas atividades ecológicas, logo pode gerar informação sobre gastos, resultados e passivos envolvidos com a sustentabilidade ecológica do negócio.

Segundo Hochman (1998), existe o papel do contador no reconhecimento do passivo ambiental nas empresas. Mas Sullivan (2005) reflete sobre as incertezas e riscos associados ao estimar o passivo ambiental. Para Williams e Phillips (1994), uma das maiores dificuldades para o contador é estimar o passivo ambiental. Para estimá-lo é necessário conhecer o fato gerador dos gastos ambientais. Também para Wood (1998), a mensuração do passivo ambiental depende da mensuração dos gastos ambientais.

Então, para informar sobre os gastos, resultados e passivos relacionados à sustentabilidade ecológica, há necessidade de se ter conhecimento sobre o evento relacionado com o fato gerador do gasto ambiental. Não obstante, surge a seguinte questão: Que tipo de evento pode estar relacionado com o fato gerador dos gastos ambientais?

$\mathrm{Na}$ tentativa de responder esse questionamento e melhorar a qualidade da informação divulgada sobre a sustentabilidade ecológica das empresas, o objetivo 
deste trabalho é investigar, analisar e identificar o tipo de evento relacionado com o fato gerador do gasto ambiental.

$\mathrm{O}$ trabalho adota a seguinte hipótese: $\mathrm{O}$ fato gerador do gasto ambiental está relacionado com a emissão de resíduos líquidos, gasosos e sólidos na concepção, fabricação, distribuição, uso e descarte dos produtos e serviços ofertados pelas empresas.

Seguindo esse raciocínio, ser sustentável ecologicamente significa a empresa conseguir que os resíduos emitidos na concepção, na fabricação, na distribuição, no uso e no descarte de seus produtos e serviços não agridam a sustentabilidade dos ecossistemas envolvidos com seu negócio.

Este trabalho considera que o fato gerador do gasto ambiental surge quando a empresa, devido a uma obrigação legal, contratual, política, voluntária ou estratégica, se compromete em implementar atividades que reduzam o consumo de insumos; transformem esses resíduos em novos insumos; transformem resíduos em novos produtos e serviços; reduzam a emissão de resíduos e neutralizem o efeito tóxico desses resíduos.

\section{Metodologia da Pesquia}

O trabalho científico pode ser abordado por diferentes métodos. Segundo Marconi e Lakatos (2001; p. 106), os principais métodos de abordagem de um trabalho científico são o método indutivo (conexão ascendente); o método dedutivo (conexão descendente); o método hipotético-dedutivo (formulação de hipóteses e conexão descendente); e o método dialético.

Identificado o método de abordagem, deve ser escolhido um método de procedimento. Marconi e Lakatos (2001; p. 106) citam alguns métodos de procedimentos como o histórico, o comparativo, o monográfico ou o estudo de caso ou de multicasos, o estatístico, o tipológico, o funcionalista, o estruturalista e o etnográfico.

Este trabalho utiliza o método de abordagem hipotético-dedutivo e o método de procedimento estudo de multicasos para alcançar o objetivo e testar a hipótese formulada. São utilizadas as técnica de observação e análises de conteúdos.

De acordo com Gil (1996; p. 121), o método de estudo de caso ou multicasos pode ter quatro etapas: delimitação da unidade caso; coleta de dados; análise e interpretação de dados e redação do relatório.

Essas fases são identificadas no estudo de multicasos deste artigo. Primeiro, são escolhidas as empresas - delimitação da unidade caso; em seguida, o trabalho analisa os projetos premiados pelo Guia de Boa Cidadania Corporativa (2005) na categoria Práticas de Destaque no tema Meio Ambiente - coleta de dados; depois, 
são comparadas as características das atividades desses projetos premiados com os caracteres das atividades do conceito O Sistema Empresa Ecoeficiente (proposta elaborada por este artigo) - análise e interpretação de dados; e, finalmente, são descritos os resultados do estudo de multicasos, testada a hipótese formulada por este artigo e as conclusões apresentadas - redação do relatório.

Visando responder à pergunta de pesquisa e testar a hipótese formulada, este trabalho analisa as características das atividades dos projetos premiados pelo Guia de Boa Cidadania Corporativa (2005) na categoria Práticas de Destaque no tema Meio Ambiente, comparando-as com as características das atividades do conceito O Sistema Empresa Ecoeficiente, e verificar se reduzem o consumo de insumos, transformam resíduos em novos insumos ou em novos produtos e serviços, reduzem a emissão desses resíduos e neutralizam seus efeitos tóxicos.

O tema Meio Ambiente no mundo corporativo é multidisciplinar. A seguir, são explanados alguns temas, explicado o conceito O Sistema Empresa Ecoeficiente e descritos e analisados os resultados do estudo de multicasos.

\section{Referencial Teórico}

\subsection{Desenvolvimento Sustentável}

De acordo com Callenbach (1999), os investidores e acionistas estão, com o passar do tempo, utilizando indicadores de sustentabilidade ecológica, no lugar da estrita rentabilidade, como critério para avaliar o posicionamento estratégico de longo prazo das empresas.

Seguindo esse mesmo raciocínio, Donaire (1999) explica que os indicadores sobre a contribuição da empresa ao desenvolvimento sustentável e de enriquecimento dos acionistas podem ser utilizados de forma complementar para informar a capacidade de retorno de um investimento.

Bebbington e Gray (2001) também refletem sobre a necessidade de as empresas conscientes de sua responsabilidade social inserirem o conceito de desenvolvimento sustentável na elaboração dos relatórios contábeis.

A ONU (2001) explica que, à medida que a sustentabilidade começa a ser um dos objetivos de um negócio importante para a gestão do risco e para o controle dos processos, os auditores das demonstrações financeiras ficam cada vez mais interessados nas informações sobre a contribuição da empresa ao desenvolvimento sustentável.

A ONU (2001), no pronunciamento de sua Comissão Mundial sobre o Meio Ambiente, no ano de 1987, por meio de um documento chamado Our Common Future, define desenvolvimento sustentável da seguinte forma: "Desenvolvimento sustentável é desenvolvimento que satisfaz as necessidades do 
presente sem comprometer a capacidade das futuras gerações satisfazerem suas próprias necessidades".

Desenvolver sustentavelmente significa promover o desenvolvimento econômico concomitantemente à preservação do meio ambiente, ou melhor, satisfazer as necessidades das sociedades presentes sem comprometer a capacidade das sociedades futuras em satisfazer suas próprias necessidades.

O termo desenvolvimento sustentável define como práticas empresariais sustentáveis aquelas que conseguem oferecer produtos e serviços que satisfaçam as necessidades de seus clientes, geram valor aos acionistas e à sociedade sem comprometer a continuidade da empresa e da sustentabilidade ecológica dos ecossistemas relacionados com o negócio.

Enfim, negócios que consigam se manter lucrativos, mas sem agredir o equilíbrio da sociedade e sem comprometer a sustentabilidade ecológica dos sistemas vivos. Isso pode ser alcançado, baseando-se nos conceitos da ecoeficiência.

\subsection{Ecoeficiência}

Hansen e Mowen (2001) utilizam o conceito da ecoeficiência como motivo e para explicar a necessidade de as empresas produzirem de forma mais ecológica e afirmam que as melhorias nos desempenhos ecológicos e econômicos podem e devem ser complementares; a melhoria no desempenho ambiental pode ser vista como uma questão de necessidade competitiva; o conceito de ecoeficiência é complementar ao desenvolvimento sustentável; e um aumento na eficiência operacional é proveniente de bom desempenho ambiental.

As exigências dos clientes são por produtos mais limpos, fabricados sem degradar o meio ambiente e cuja concepção, fabricação, distribuição, uso e descarte sejam inofensivos ao meio ambiente; a preferência dos bons empregados em trabalhar para empresas responsáveis ecologicamente estimula a produtividade; menores custos de seguros e de capital para empresas ecologicamente corretas; ocorrência de benefícios sociais, facilidade na venda de seus produtos e serviços, inovações e novas oportunidades como consequência de bom desempenho ambiental; redução de custos; e aumento de receitas são todos incentivos para o aumento na eficiência operacional e ambiental das empresas.

Para o WBCSD - World Business Council for Sustainable Development (1992 apud CEBDS, 2006), ecoeficiência significa as empresas fornecerem bens e serviços a preços competitivos, satisfazendo as necessidades humanas com qualidade de vida, reduzindo o impacto ambiental e o consumo de recursos ao longo do ciclo de vida de forma a operar em equilíbrio com a capacidade de 
sustentação estimada da Terra.

Segundo Araújo (2005), a subsidiária brasileira da alemã Basf, em parceria com GTZ (agência do governo alemão para a cooperação internacional), inaugurou um centro de excelência para o desenvolvimento sustentável com a finalidade de ensinar outras empresas a trabalharem com o conceito de educação ambiental, reflorestamento e ecoeficiência.

Para Burritt e Saka (2005), a ecoeficiência é uma medida que fornece informações monetárias junto com indicadores não monetários para avaliarem o desempenho ambiental das companhias.

Portanto, empresa ecoeficiente, para este trabalho, é aquela capaz de oferecer seus produtos e serviços consumindo os recursos de maneira eficiente, transformando os resíduos em novos insumos ou em novos produtos e serviços, reduzindo a emissão de resíduos e neutralizando o efeito tóxico dos resíduos de forma a não comprometer a capacidade de sustentação dos ecossistemas terrestres.

Nessa busca por ecoeficiência, as empresas investem em atividades onde incorrem em gastos. Estes em ecoeficiência podem ser chamados de gastos ambientais.

\subsection{Gastos Ambientais}

Baseado em relatório da ONU (1997, apud Ribeiro e Lisboa, 2000), o gasto ambiental surge quando a empresa se compromete, por meio de uma obrigação legal, contratual, política, voluntária ou estratégica, a implementar atividades ecológicas para reduzir o consumo de insumos, transformar resíduos em novos insumos ou em novos produtos e serviços, para reduzir a emissão desses resíduos e para neutralizar seus efeitos tóxicos.

Nos trabalhos do Environmental Protection Agency - EPA (1995), EPA (1995b) EPA (1997) e no da ONU (2001), os pesquisadores definem o conceito de gastos ambientais como sendo o dispêndio de capital incorrido em atividades ambientais.

No entanto, os trabalhos do EPA não identificam o fato gerador dos gastos ambientais. Já o trabalho da ONU (2001), conforme a Figura 2, pode ser utilizado para identificar o evento relacionado com o fato gerador dos gastos ambientais:

Segundo a Figura 2, há entradas (input) de $100 \mathrm{~kg}$ de material no sistema empresa. Esse material é transformado nas seguintes saídas (output e output não produto): $12 \mathrm{~kg}$ de produto (output); $29 \mathrm{~kg}$ de emissões gasosas (output não produto); $43 \mathrm{~kg}$ de resíduos sólidos (output não produto); e $16 \mathrm{~kg}$ de águas residuais (output não produto). Ou seja, a empresa utilizou $100 \mathrm{~kg}$ de material (inputs) para produzir $12 \mathrm{~kg}$ de produto (outputs) e $88 \mathrm{~kg}$ de resíduos (outputs não produto). 
Figura 2: Fluxos de materiais e financeiros numa fábrica de tintas

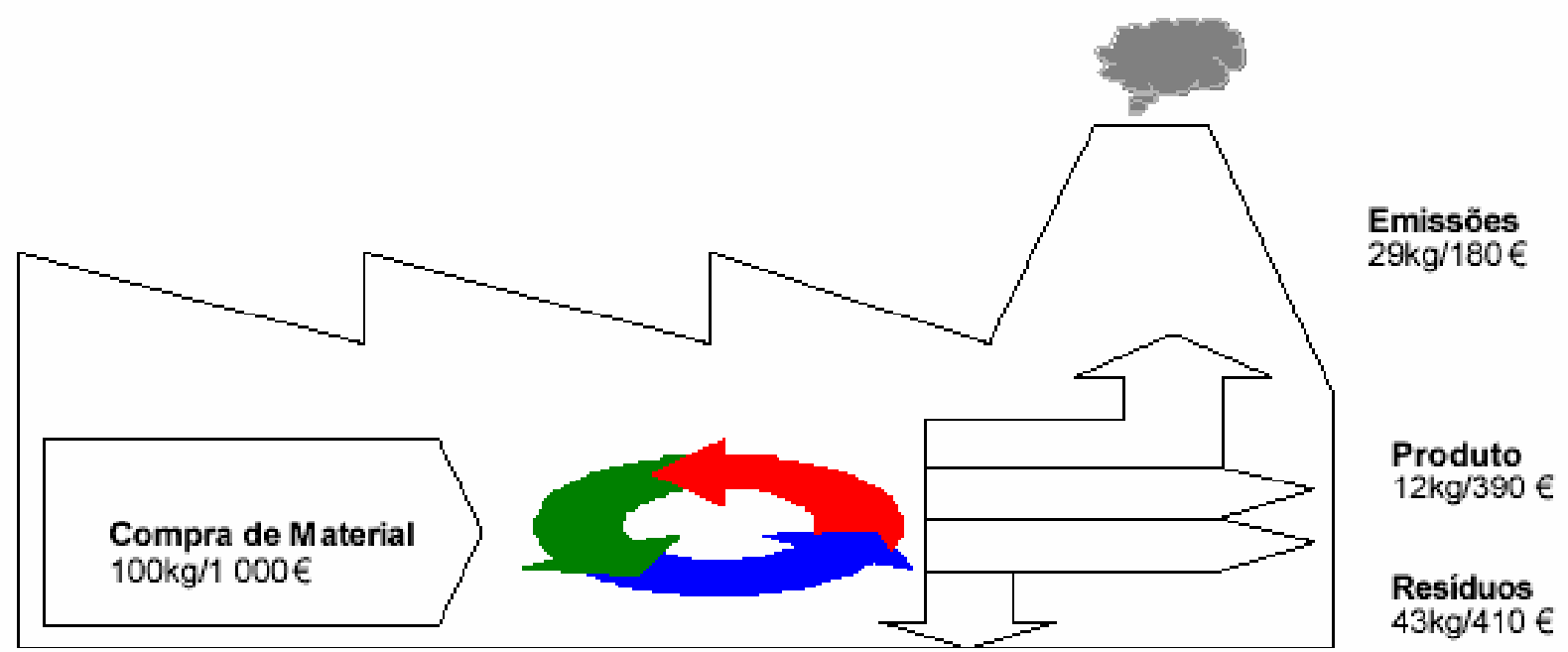

Águas residuais $16 \mathrm{~kg} / 20 €$

Fonte: Dimitroff/Jasch/Schnitzer,(1997, apud ONU, 2001).

Financeiramente, os recursos consumidos custam $1000 €$. Desse total de recursos, somente $390 €$ podem ser vendidos. O restante, $610 €$, pode representar perdas se não são revertidos em novos inputs, em novos outputs e se o resíduo for tóxico para a sustentabilidade ecológica.

Observe que os recursos (inputs) injetados no sistema empresa são liberados em forma de produtos (outputs), serviços (outputs) e resíduos (outputs não produto). Esses resíduos, na verdade, são desperdícios. Analisando os processos biológicos da natureza, nada se cria nem se perde, tudo se transforma, e, por isso, a geração de resíduo nada mais é do que desperdício, ineficiência do processo produtivo. Ou seja, resíduos significam desperdícios de material e consequentemente perda monetária.

Esse desperdício é emitido na forma líquida e/ou gasosa e/ou sólida, podendo se transformar em poluição quando seu efeito tóxico sobre a sustentabilidade ecológica não é neutralizado. Nem todo resíduo é poluição, pois, por meio das atividades ecológicas, podem ser transformados em novos insumos ou em novos produtos e serviços. Já, quando seu efeito tóxico atinge a sustentabilidade, a poluição é gerada.

As atividades ecológicas podem ser implementadas para reduzir o consumo do insumo, transformar resíduos sólidos, líquidos e gasosos (output não produto) em novos insumos (inputs), em novos produtos e serviços (outputs), reduzir a emissão desses resíduos e neutralizar seu efeito tóxico no meio ambiente.

Baseado em Capra (2000, apud Vellani, 2004), na ONU (2001), em Burritt e Saka b, (2004), no CEBDS (2006), em Hansen e Mowen (2001) e em Ribeiro 
(1998), este trabalho elabora a proposta O Sistema Empresa Ecoeficiente para demonstrar prováveis características das atividades ecológicas onde podem ser incorridos os gastos ambientais conforme a Figura 3.

Figura 3: O Sistema Empresa Ecoeficiente

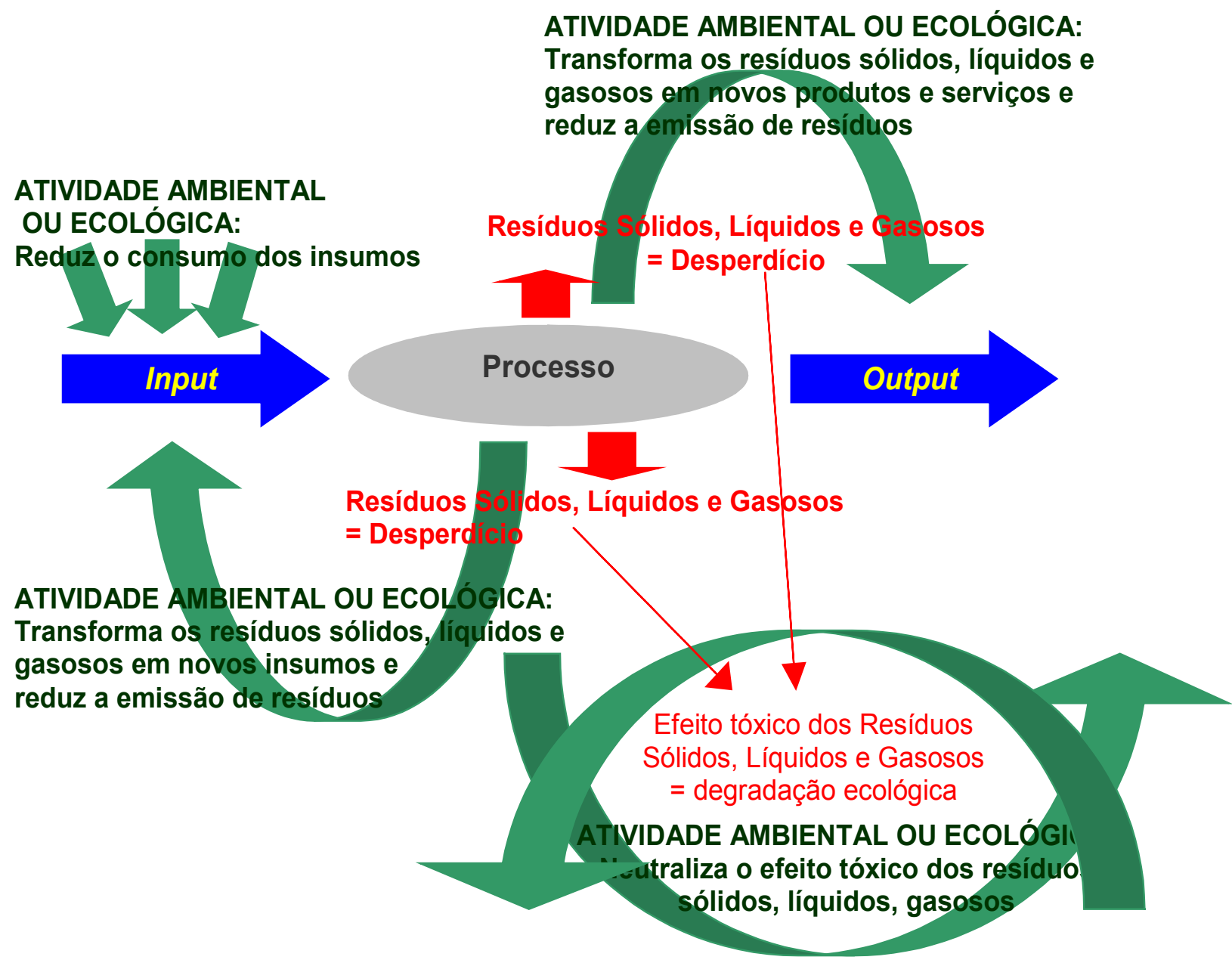

Fonte: Elaborada pelos autores.

Nessa proposta chamada de Sistema Empresa Ecoeficiente, a atividade ambiental ou ecológica pode tornar a empresa mais ecoeficiente ao diminuir o desperdício, reduzindo o uso dos insumos, transformando resíduos sólidos, líquidos e gasosos (output não produto) em novos insumos (inputs) ou em novos produtos e serviços (outputs), reduzindo a emissão desses resíduos e neutralizando seus efeitos tóxicos.

Ocorrendo essas reduções no uso dos insumos e na emissão de resíduos, essas transformações em novos insumos ou em novos produtos e serviços e essas neutralizações dos efeitos tóxicos, a empresa pode reduzir gastos ao utilizar menos insumos, ao reaproveitar os resíduos como insumos, ao vender os resíduos recicláveis ou reciclados e evitar multas e indenizações ao recuperar áreas degradadas e se adequar à legislação ambiental.

Nesse sentido, gastos em atividades ecológicas podem gerar resultados. 
Conforme Vellani e Nakao (2003), gastos em ecoeficiência podem reduzir custos gerando vantagem competitiva.

Os gastos envolvidos com a sustentabilidade no bottom line ambiental podem ser os gastos ambientais. Vellani (2004; p. 51), Ribeiro (1998) e Ribeiro (2005) explicam que proteger o meio ambiente significa que a empresa incorre em gastos ambientais para manter a sustentabilidade ecológica dos negócios.

Gastos ambientais, para este trabalho, podem ser o total de recursos consumidos pelas atividades ecológicas para reduzir o consumo de recursos (inputs), transformar resíduos líquidos, gasosos e sólidos (outputs não produtos) em novos insumos (novos inputs) ou em novos produtos (novos outputs), para reduzir a emissão de resíduos e para neutralizar o efeito tóxico desses resíduos.

A Contabilidade da gestão ambiental pode ser a responsável pela identificação, registro, acúmulo, controle, mensuração e evidenciação do efeito financeiroeconômico desses gastos ambientais no patrimônio e no resultado da empresa.

Conforme Ribeiro e Carvalho (2000b), a Contabilidade da gestão ambiental significa a aplicação de alguns conceitos para obter os relatórios da Contabilidade que dão ênfase especial aos eventos e às transações envolvidas com a sustentabilidade ecológica. Contabilidade da gestão ambiental gerencia os gastos e resultados incorridos nas atividades ecológicas.

Vellani, Nakao e Ribeiro (2004) afirmam que a Contabilidade da gestão ambiental pode buscar novos conceitos e novas formas de demonstrar o desempenho de uma atividade ecológica visando à sustentabilidade ecológica do negócio. Kolk e Mauser (2003) apresentam elementos e conclusões para melhorar os sistemas de avaliação de desempenho ecológica das companhias.

Sustentabilidade ecológica significa, para este trabalho, que a empresa consegue fornecer produtos e serviços sem agredir a sustentabilidade ecológica do planeta implementando atividades ecológicas para reduzir o consumo de insumos, reduzir a emissão de resíduos, transformar esses resíduos em novos insumos ou em novos produtos e serviços e neutralizar o efeito tóxico desses detritos.

Para este artigo, o fato gerador do gasto ambiental - gasto em atividades em prol da sustentabilidade ecológica - está relacionado com a emissão de resíduos líquidos, gasosos e sólidos na concepção, fabricação, distribuição, uso e descarte dos produtos e serviços ofertados pelas empresas, pois, quando a empresa busca a sustentabilidade no bottom line ambiental, cria uma obrigação em ser mais ecoeficiente e contribuir ao desenvolvimento sustentável.

A seguir, o trabalho analisa se as características das atividades dos projetos divulgados no Guia Exame Boa Cidadania Corporativa (2005) são semelhantes às características das atividades ecológicas do conceito O Sistema Empresa Ecoeficiente. 
A CSR (2006) considera que a responsabilidade social não possuiu uma definição universal e pode ser percebida pelo setor privado como uma maneira de integrar a variável econômica, social e ecológica. A CES-FGV (2006) e a Sustainablemeasures (2006) considera que a sustentabilidade pode ter três dimensões: social, econômica e ambiental, conhecidas internacionalmente no mundo dos negócios como Triple Bottom Line (TBL) da sustentabilidade.

Com base nessas considerações do CSR (2006), da CES-FGV (2006) e da Sustainablemeasures (2006), este trabalho considera que o conceito de responsabilidade social e o de sustentabilidade almejam o mesmo objetivo: integrar os negócios, a sociedade e os ecossistemas na busca pelo desenvolvimento sustentável. Sustentabilidade ecológica e responsabilidade social na dimensão da relação com o meio ambiente são constituídas pelas mesmas atividades e ambas necessitam da ecoeficiência.

Por isso, se as atividades dos casos práticos são consideradas como atividades relacionadas com a responsabilidade social na dimensão relação com o meio ambiente, isso denota que estão considerando-as como atividades de sustentabilidade do bottom line ambiental.

Portanto, constatar se as atividades desses casos práticos possuem características semelhantes às características das atividades consideradas como ecológicas pelo conceito O Sistema Empresa Ecoeficiente significa, para este artigo, verificar se cada projeto tem relação com a sustentabilidade ecológica do negócio.

No Guia de Boa Cidadania Corporativa 2005, há 74 projetos premiados como práticas de destaque no tema Meio Ambiente com a descrição das características das atividades empresariais envolvidas com cada um.

Essas características são analisadas por este trabalho para verificar se as ações tomadas em cada projeto premiado, realmente, contribuem para a proteção do meio ambiente dos resíduos emitidos na concepção, fabricação, uso e descarte dos produtos e serviços ofertados pelas empresas.

Conforme a proposta do conceito O Sistema Empresa Ecoeficiente, uma empresa ecológica é aquela que investe em ações para controlar a relação entre o sistema empresa e o meio ambiente.

Portanto, para este trabalho, as atividades ecológicas que visam à sustentabilidade ecológica dos negócios têm as mesmas características das atividades ecológicas do conceito O Sistema Empresa Ecoeficiente. Essas atividades visam reduzir o consumo dos insumos, transformar resíduos em novos insumos ou em novos produtos e serviços, reduzir a emissão dos resíduos e neutralizar seus efeitos tóxicos.

O trabalho analisa as características de todos os projetos premiados como 
práticas de destaque no tema Meio Ambiente para verificar se as atividades neles desenvolvidas estão relacionadas com as consideradas, por este trabalho, como ecológicas (ambientais).

A Figura 4 resume o resultado:

Figura 4: Análise das práticas de destaque no tema meio ambiente

\begin{tabular}{|c|c|c|c|}
\hline Enpresas & Projetos & $\begin{array}{c}\text { Práticas de destaque com características } \\
\text { semelhantes às do conceito } \\
\text { Sistema Empresa Eco-eficiente }\end{array}$ & $\begin{array}{c}\text { Práticas de destaque com caracteristicas } \\
\text { diferentes das do conceito } \\
\text { Sistema Enpresa Eco-eficiente }\end{array}$ \\
\hline \hline 49 & 74 & 33 & 41 \\
\hline
\end{tabular}

Fonte: Elaborada pelos autores.

Das 74 práticas de destaques, $33(45 \%)$ apresentam características do conceito O Sistema Empresa Ecoeficiente. Baseado nesse conceito, este trabalho considera que os outros projetos, 41 (55\%), têm características de sustentabilidade, mas relacionados com um bottom line diferente do ecológico.

Como exemplo, são apresentadas que, num dos projetos premiados como prática de destaque no tema Meio Ambiente, as atividades nele desenvolvidas são para incentivar a preservação ambiental de um parque público por meio da educação. Observa-se que os gastos nesses projetos são incorridos em atividades sem relação com os processos da empresa. Não transformam resíduos em novos insumos ou em novos produtos e serviços, não reduzem o consumo dos insumos, não reduzem a emissão de resíduos e nem neutralizam o efeito tóxico dos resíduos, e não tornam a empresa mais ecoeficiente. Esse projeto tem mais característica de um projeto de sustentabilidade no bottom line social ao satisfazer os desejos da coletividade, nesse caso, a educação para preservar um parque público.

Num outro projeto, há gastos com atividades relacionadas com os valores da empresa, com a cultura empresarial, como, por exemplo, manter belos jardins pela empresa ou programas especiais para clientes ecologicamente corretos. Se essa cultura envolve proteção ambiental, não significa incorrer em gastos ambientais. Para este trabalho, se as atividades de certo projeto não têm relação com as atividades ecológicas do conceito O Sistema Empresa Ecoeficiente, os gastos nelas incorridos não são considerados como gastos ambientais e, portanto, gastos com jardinagem não são considerados como ações em prol da sustentabilidade ecológica do negócio, a não ser que o jardim seja uma estação de tratamento de efluentes.

Também há casos de gastos com o intuito de educar os colaboradores internos sobre algum tema. Mesmo esse tema sendo sobre meio ambiente, alguns projetos têm mais proximidade com a sustentabilidade social relacionada com a 
educação dos colaboradores internos. Já os gastos incorridos num treinamento que ensine os executivos a gerenciar os resíduos da empresa são considerados, por este trabalho, como gastos ambientais.

Há também, nas práticas de destaque no tema Meio Ambiente do guia, exemplo de empresas que implementam atividades para manter uma área nativa próxima a sua unidade fabril e programas de educação ambiental à comunidade informando os gastos incorridos nessas atividades como gasto em atividade ecológica.

Nota-se que, no caso de se manter uma área nativa ou um programa de educação ambiental à comunidade, a empresa está satisfazendo os desejos da coletividade e contribuindo para a melhoria da sociedade, mas não cuida da relação empresa-meio ambiente. Por isso, pode ser considerado como investimento em sustentabilidade social, mas não em sustentabilidade ecológica.

Se todos os gastos incorridos em atividades relacionadas com o meio ambiente forem gastos ambientais, então uma indústria de reciclagem tem somente gastos com atividades ecológicas. Porém, nesse caso, somente os gastos incorridos em atividades ligadas à proteção do meio ambiente dos resíduos emitidos pela indústria podem ser considerados por este artigo como gastos ambientais.

Utilizando o conceito O Sistema Empresa Ecoeficiente, o gestor interno da empresa pode visualizar as atividades que realmente operam para gerenciar a relação entre a empresa e os ecossistemas envolvidos.

\section{Considerações Finais}

A sustentabilidade pode ser visualizada como um conjunto de atitudes nos bottom lines econômico, social e ecológico. Semelhante à responsabilidade social, suas atividades colaboram para as empresas conseguirem um melhor relacionamento com todos os agentes envolvidos com seus negócios.

Os gastos incorridos nas atividades que buscam a sustentabilidade ecológica podem ser chamados de gastos ambientais pela Contabilidade. Esta, por meio de Contabilidade da gestão ambiental, pode ser a responsável por registrar, acumular, mensurar, analisar e divulgar informações sobre os eventos incorridos nas atividades ecológicas.

Visando a um melhor gerenciamento dos gastos e resultados com a sustentabilidade ecológica, este trabalho considera que os executivos das empresas podem utilizar, por ser um tema multidisciplinar, conceitos de outras áreas do conhecimento para melhor analisar os processos e atividades ecológicas dentro de uma empresa.

Para isso, o evento fato gerador dos gastos ambientais precisa ser identificado. Este trabalho, com base em conceitos de diferentes áreas do conhecimento, 
elabora um conceito chamado O Sistema Empresa Ecoeficiente para propor um limite no campo de atuação da Contabilidade da gestão ambiental e, consequentemente, identifica certas características que podem ser analisadas para identificar uma atividade ecológica.

Respondendo à pergunta de pesquisa, aceitando a hipótese formulada e com base na proposta O Sistema Empresa Ecoeficiente, o fato gerador do gasto ambiental, para este trabalho, pode ser obrigação legal, contratual, política, voluntária ou estratégica da empresa em implementar atividades ecológicas para reduzir o consumo de insumos, para transformar resíduos em novos insumos ou em novos produtos e serviços, para reduzir a emissão de detritos e para neutralizar o efeito tóxico desses resíduos na concepção, fabricação, transporte, uso e no descarte dos produtos e serviços ofertados pelos negócios.

Por causa dessa obrigação em investir em sustentabilidade ecológica, mantendo o sistema empresa em equilíbrio com os ecossistemas ao seu redor, as firmas implementam atividades ecológicas. Nessas atividades, são incorridos os gastos ambientais, sendo a Contabilidade da gestão ambiental a responsável por registrar, acumular, mensurar, analisar e divulgá-los.

As características das atividades do conceito O Sistema Empresa Ecoeficiente podem ser utilizadas como base para identificar uma atividade ecológica. Por isso, este trabalho analisa os casos práticos premiados como práticas de destaque no tema Meio Ambiente publicado no Guia de Boa Cidadania Corporativa (2005).

O resultado mostra que, das 74 práticas de destaque no tema Meio Ambiente do Guia de Boa Cidadania Corporativa (2005), 33 (45\%) possuem atividades com características semelhantes às das atividades ecológicas do conceito O Sistema Empresa Ecoeficiente.

Talvez, essa informação possa ser interpretada como um indicador da falta de compreensão dos empresários e da mídia sobre a sustentabilidade ecológica de uma empresa.

Os executivos envolvidos com a sustentabilidade ecológica, ou seja, os colaboradores da gestão ambiental, podem utilizar o conceito O Sistema Empresa Ecoeficiente para compreender o evento relacionado com o fato gerador dos gastos ambientais, das atividades ecológicas dentro de uma empresa e do campo de atuação da Contabilidade da gestão ambiental para tomar suas decisões a respeito da sustentabilidade ecológica do negócio.

De acordo com White (2005), a responsabilidade social e a sustentabilidade não são uma opção, mas, sim, uma realidade, ou seja, a sustentabilidade é uma necessidade empresarial e uma oportunidade de vantagem competitiva. Por isso, as empresas podem utilizar a Contabilidade da gestão ambiental para gerenciarem os eventos relacionados com a sustentabilidade em relação ao bottom 
line ambiental.

As empresas brasileiras já trilham o caminho da sustentabilidade ecológica, no entanto ainda têm dificuldades de compreender a relação da empresa com o meio ambiente e o fato gerador dos gastos ambientais. Por isso, há a necessidade de muitos estudos para a compreensão dos empresários sobre a sustentabilidade ecológica e o papel da Contabilidade da gestão ambiental.

Contudo, por meio do conceito O Sistema Empresa Ecoeficiente, este trabalho limita a campo de atuação da Contabilidade da gestão ambiental, identifica um possível fato gerador dos gastos ambientais e prováveis características das atividades ecológicas dentro de uma empresa. Vamos padronizar a Contabilidade da Gestão Ambiental? Vellani e Ribeiro (2009) propuseram um padrão de organização das atividades ambientais para gerenciar a ecoeficiência de qualquer negócio. Sugerem-se estudos futuros com o uso desse padrão.

\section{Referências}

ARAÚJO, Alexandre. A ordem é o eco-eficiência. Guia Exame 2005: Boa Cidadania Corporativa. São Paulo: Abril, 2005.

BEBBINGTON, Jan. Sustainable development: a review of the internacional development, business and accounting literature. Univ. of Aberdeen Acct, Finance \& Mgmt Working Paper No. 00-17. University of Aberdeen - Business School: UK, 2001.

BEBBINGTON, Jan; GRAY, Rob. Accounts of sustainable development: the construction of meaning within environmental reporting. Aberdeen Papers in Acct, Finance and Mgmt Working Paper No. 00-18. UK, 2001.

BURRITT, Roger L.; SAKA B, Chika. Environmental management accounting applications and eco-efficiency: case studies from Japan. Article Journal of Cleaner Production, In Press, Corrected Proof, Available online 12 October 2005

CALLENBACH, Ernest et al. Gerenciamento Ecológico: guia do Instituto Elmwood de Auditoria Ecológica e Negócios Sustentáveis. 12. ed. São Paulo: Cultrix, 1999.

CEBDS - Conselho Empresarial Brasileiro para o Desenvolvimento Sustentável. Ecoeficiência. Brasil, 2006. Disponível em: http://www.cebds.org.br/cebds/ecorbe-ecoeficiencia.asp. Acesso em: 13/02/2006.

CES - CENTRO DE ESTUDOS EM SUSTENTABILIDADE. Institucional, apresentacão. Fundação Getúlio Vargas. Brasil, 2006. Disponível em: http:// 
ces.fgvsp.br/? fuseaction $=$ content $\&$ IDassunto=43\&IDidioma=1. Acesso em: 09/03/2006.

CSR - Corporate Social Responsibility Corporate Social Responsibility: home. Canadá, 2006. Disponível em: http://strategis.ic.gc.ca/epic/internet/incsr-rse.nsf/ en/Home. Acesso em: 03/03/2006.

DERWALL, Jeroen et al. Socially responsible investing: the eco-eficiency premium puzzle. EFMA 2004 Basel Meetings Paper; Erasmus University Working Paper. Nederlands, 2004.

DONAIRE, Denis. Gestão Ambiental na Empresa - 2. ed. São Paulo: Atlas, 1999.

EPA - ENVIRONMENTAL PROTECTION AGENCY. An Introduction to Environmental Accounting as a Business Management Tool: Key Concepts and Terms. United States Environmental Protection Agency. Washington, D.C.: EPA, 1995.

EPA - ENVIRONMENTAL PROTECTION AGENCY. Environmental Accounting Case Studies: green accounting at AT\&T. United States Environmental Protection Agency. Washington, D.C.: EPA, 1995 b.

EPA - ENVIRONMENTAL PROTECTION AGENCY. Environmental Cost Accounting for Chemical and Oil Companies: A Benchmarking Study. United States Environmental Protection Agency. Washington, D.C.: EPA, 1997.

ETHOS - Instituto Ethos de Empresas e Responsabilidade Social. Temas e indicadores. Brasil, 2006. Disponível em: http://www.ethos.org.br/docs/conceitos_praticas/indicadores/temas/. Acesso em: 13/02/2006.

GIL, A. C. Como elaborar projetos de pesquisa. São Paulo: Atlas, 1993.

GUIA EXAME DE BOA CIDADANIA CORPORATIVA. Práticas de destaque: meio ambiente. Brasil, 2005. 6 V., dezembro, 2005.

HANSEN, Don R.; MOWEN, Maryanne M. Gestão de Custos. São Paulo: Pioneira Thomson Learning, 2001.

HOCHMAN, Joel A. Cleaning up environmental accounting. The National Public Accounting. Washington: Jun 1998.Vol.43, Iss. 4; p. 20, 4 p.

KATES, Robert et al. Sustainability Science. KSG Working Paper No. 00-018. EUA, 2003. 
LAKATOS, E. M.; MARCONI, M. de A. Metodologia do trabalho cientifico. São Paulo: Atlas, 2001.

LUDEVID, Manuel. Contabilidad ambiental: medida, evaluación y comunicación de la actuación ambiental de la empresa. Fundación Fòrum Ambiental e Agencia Europea del Medio Ambiente: Barcelona, 1999.

KOLK, Ans; MAUSER, Anniek. The Evolution of Environmental Management: From Stage Models to Performance Evaluation. Business Strategy and the Environment, Vol. 11, p. 14-31, October, 2003.

ONU - Organização das Nações Unidas. Contabilidade da Gestão Ambiental: Procedimentos e Princípios. Divisão para o Desenvolvimento Sustentável das Nações Unidas, Nações Unidas: Nova York, 2001. Disponível em: http://www.un.org/ esa/sustdev/sdissues/technology/emaportuguese.pdf. Acesso em: 01/04/2005.

RIBEIRO, Maisa de Souza. Contabilidade Ambiental. São Paulo: Ed. Saraiva, 2005.

RIBEIRO, Maisa de Souza. Custeio das Atividades de Natureza Ambiental. Tese de Doutorado. São Paulo: FEA/ USP, 1998.

RIBEIRO, Maisa de Souza; CARVALHO, L. Nelson de. The accounting information as a support to sustainable development. Sustainable City International Conference, abril de 2000a.

. Environmental accounting: instrument of environmental management. 2000 ABO Research Conference, American Accounting Association. ChicagoIllinois. EUA, 2000b.

SULLIVAN, Edward. Estimating Environmental Liabilities: One Price Does Not Fit All. Risk Management; Jul 2005; 52, 7; ABI/INFORM Global p. 24.

SUTAINABLEMEASURES. What is an indicator of sustainability? Sustenaible measures. West Hartford, 2006. Disponível em: http://www.sustainablemeasures.com/Indicators/WhatIs.html. Acesso em: 09/03/2006.

VELLANI, C. L. Contabilidade Ambiental: Uma Contribuição da Ciência Contábil para o Desenvolvimento Sustentável. Monografia de conclusão de curso de graduação em Ciências Contábeis, apresentada à Faculdade de Economia, Administração e Contabilidade de Ribeirão Preto - SP - FEARP/USP: Ribeirão Preto: FEARP/USP, 2004. 
VELLANI. C. L.; NAKAO, S. H. Investimentos Ambientais e Redução de Custos. In: Congresso USP de Contabilidade e Controladoria, $3^{\circ}$, 2003, São Paulo-SP. Anais... Brasil: ( ), 2003. 1CD.

VELLANI, C. L.; NAKAO, S.; RIBEIRO, M. S. A avaliação de programas ambientais e a Contabilidade. In: Congresso Brasileiro de Custos. XI., 2004, Porto Seguro-BA. Anais...Brasil: ( ), 2004. 1CD.

VELLANI, C. L.; RIBEIRO, M. de S. Sistema contábil para gestão da ecoeficiência empresarial. Revista Contabilidade e Finanças, v. 20, n. 49, janeiro/abril 2009.

WHITE, Allen L. Fade, Integrate or Transform? The Future of Corporate Social Reporting. Business for Social Responsability. EUA, 2005. Disponível em: http://www.bsr.org/. Acesso em: 03/03/2006.

WILLIAMS, Georgina; PHILLIPS, Thomas J. Jr. Cleaning up our act: accounting for environmental liabilities. Business Credit. Jul/Aug 1994; 96, 7.

WOOD, Dorothy. Environmental liabilities: is a standard needed? Australian CPA. Dec. 1998; 68; 11; ABI/INFORM Global p. 53. 